\title{
Tungsten erosion in the outer divertor of JET
}

\author{
M. Mayer ${ }^{\mathrm{a}}$, J. Likonen ${ }^{\mathrm{b}}$, J.P. Coad ${ }^{\mathrm{c}}$, H. Maier ${ }^{\mathrm{a}}$, M. Balden ${ }^{\mathrm{a}}$, \\ S. Lindig ${ }^{\mathrm{a}}$, E. Vainonen-Ahlgren ${ }^{\mathrm{b}}$, V. Philipps ${ }^{\mathrm{d}}$, and \\ JET-EFDA Contributors \\ ${ }^{a}$ Max-Planck-Institut für Plasmaphysik, EURATOM Association, Boltzmannstr. 2, \\ D-85748 Garching, Germany \\ ${ }^{\mathrm{b}}$ VTT, Association EURATOM/TEKES, P.O. Box 1000, FI-02044 VTT, Finland \\ ${ }^{\mathrm{c}}$ UKAEA/EURATOM Fusion Association, Culham Science Centre, Abingdon, \\ Oxon, OX14 3DB, United Kingdom \\ ${ }^{\mathrm{d}}$ Institut für Plasmaphysik, Forschungszentrum Jülich GmbH, EURATOM \\ Association, Trilateral Euregio Cluster, D-52425 Jülich, Germany
}

\begin{abstract}
Erosion of tungsten in the outer JET divertor was determined with a set of tungsten coated divertor tiles during the 2001-2004 discharge campaign. The tungsten marker was strongly eroded, with the largest erosion at the outer strike point position, where more than $75 \%$ of the initial W disappeared. Strong erosion is also observed at the outer baffle and horizontal apron of tile 8, where about half of the tungsten has been removed. These numbers are lower boundaries, because the $\mathrm{W}$ was locally completely eroded. The tungsten erosion is inhomogeneous on a microscopic level and depends on the micro-topography of the rough surface: large erosion with complete disappearance of the $\mathrm{W}$ layer is observed on plasma-facing areas of microscopic ridges, while a smaller erosion and sometimes even deposition of carbon is found on the far side of ridges and in pores.
\end{abstract}

PACS: 52.40.Hf; 52.55.Fa; 82.80.Yc; 82.80.Ms

Corresponding author: M. Mayer, Max-Planck-Institut für Plasmaphysik, Boltzmannstr. 2, D-85748 Garching, Germany, Matej.Mayer@ipp.mpg.de

Presenting author: M. Mayer, Matej.Mayer@ipp.mpg.de

\section{Introduction}

Erosion, subsequent plasma transport, and redeposition of first wall materials leads to a modification of plasma facing components and has a critical effect on component lifetime and fuel inventories. Thick layers of redeposited 
material are observed in the inner divertor legs of current divertor tokamaks: Carbon/beryllium layers at JET [1-3], and carbon/boron layers at ASDEX Upgrade [4] and DIII-D [5]. Beryllium and boron originate from regular beryllium evaporations or boronizations for wall conditioning in the main plasma chamber. It is known from investigations with long term samples at the main chamber wall [6] and from spectroscopy [7] that wall material is eroded from the main chamber walls and transported to the inner divertor [8]. This is confirmed by ${ }^{13} \mathrm{CH}_{4}$ puff experiments in the main chamber $[9,10]$ : The ${ }^{13} \mathrm{C}$ is found to be predominantly redeposited in the inner divertor.

The situation in the outer divertor is much less clear. Erosion and deposition were determined from the shape-change of JET outer divertor tiles using a micrometer screw and showed a mixture of net erosion and deposition areas without a clear trend [1]. Erosion/deposition effects were small, with the exception of clear deposition on the shadowed area on horizontal tile 6 (see Fig. 1 for a schematic representation of the JET divertor). The DIMES probe in DIII-D showed net carbon erosion at the outer strike point under attached plasma conditions [11], and net carbon erosion was also observed in a large fraction of the outer divertor of ASDEX Upgrade [4].

Erosion/deposition in the JET divertor was investigated with a tungsten marker stripe during the campaigns 2001-2004. Tungsten is an important candidate material for the ITER divertor, and an ITER-like wall with tungsten divertor is foreseen at JET [12]. The inner divertor showed heavy deposition, and the $\mathrm{W}$ marker was used to distinguish between deposited layers and initial tiles. These results will be described elsewhere [3]. This paper focuses on the results from the outer vertical divertor tiles.

\section{Experimental}

A cross-section of the JET divertor is shown in Fig. 1. Tiles 1, 3 and 4 form the inner, and tiles 6, 7 and 8 the outer divertor. The tiles consist of a 2D carbon fibre composite (CFC), type Dunlop DMS 780. A poloidal section of tiles was coated with a $2 \mathrm{~cm}$ wide tungsten stripe with an initial thickness of 3-3.5 $\mu \mathrm{m}$ using a pulsed plasma arc [13].

The tiles were exposed from 2001-2004 (campaigns C5-C14). The total time in which the plasma was in divertor configuration was $83000 \mathrm{~s}$ within about 5500 divertor shots, while in total about 8000 shots were performed. The accumulated ion flux into the outer divertor evaluated from the integration of the Langmuir probe data, which were available for 4800 of all the 5500 divertor shots, reaches a total particle fluence of $2.3 \times 10^{27}$ ions. This would extrapolate to a fluence of $2.6 \times 10^{27}$ ions for all the 5500 divertor shots. Various plasma 


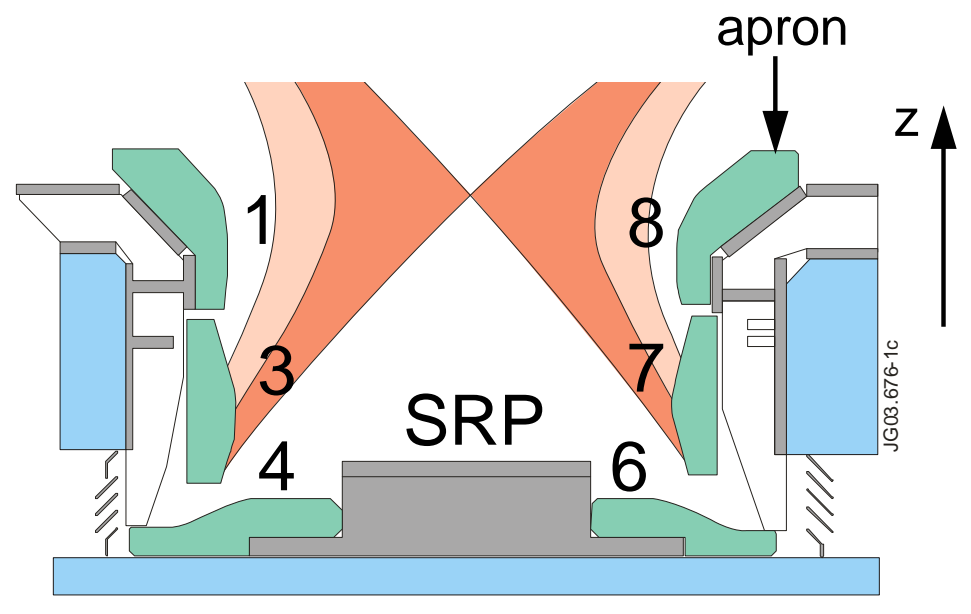

Fig. 1. Cross-section of the JET divertor in 2001-2004. Numbers are tile numbers, and SRP is the septum replacement plate. The $\mathrm{z}$-coordinate is running in vertical direction, with the zero point at the midplane of the machine.

configurations and plasma conditions have been used, including a 1 month reversed field campaign in June/July 2003 and a trace tritium campaign in September/October 2003.

The tiles were analyzed before and after exposure using Rutherford backscattering (RBS) at $165^{\circ}$ in the BOMBARDINO facility at IPP Garching. The initial analysis was performed with $2.5 \mathrm{MeV}$ protons, with some additional measurements at $3 \mathrm{MeV}$. The analysis after exposure was made with $4 \mathrm{MeV}$ protons, with some additional measurements at $3 \mathrm{MeV}$. The beam spot diameter was $1.8 \mathrm{~mm}$. The measured spectra were analyzed with the program SIMNRA $[14,15]$. Backscattering cross-section data from [16-18] for ${ }^{12} C,{ }^{13} C$, and ${ }^{16} \mathrm{O}$, respectively, were used. Due to the lack of a precise current measurement the analyzing fluence was determined from the height of the carbon bulk spectrum. Particle induced X-ray emission (PIXE) measurements were made with $4 \mathrm{MeV}$ incident protons, the amount of $\mathrm{W}$ was determined from its $\mathrm{L}_{\alpha}$ line. The PIXE measurements were not absolutely calibrated, but scaled to best fit to the RBS results.

\section{Results and discussion}

The distribution of strike point positions on tiles 7 and 8 , as determined from the magnetic reconstruction using the EFIT code, is shown in the upper part of Fig. 2. The z-coordinate is running in vertical direction (see Fig. 1). The strike point was mostly on tile 7 , and only very few discharges had the strike point on tile 8 . In addition, there were about 1978 shots with the strike point on the horizontal target (tile 6), which are not shown in Fig. 2. 


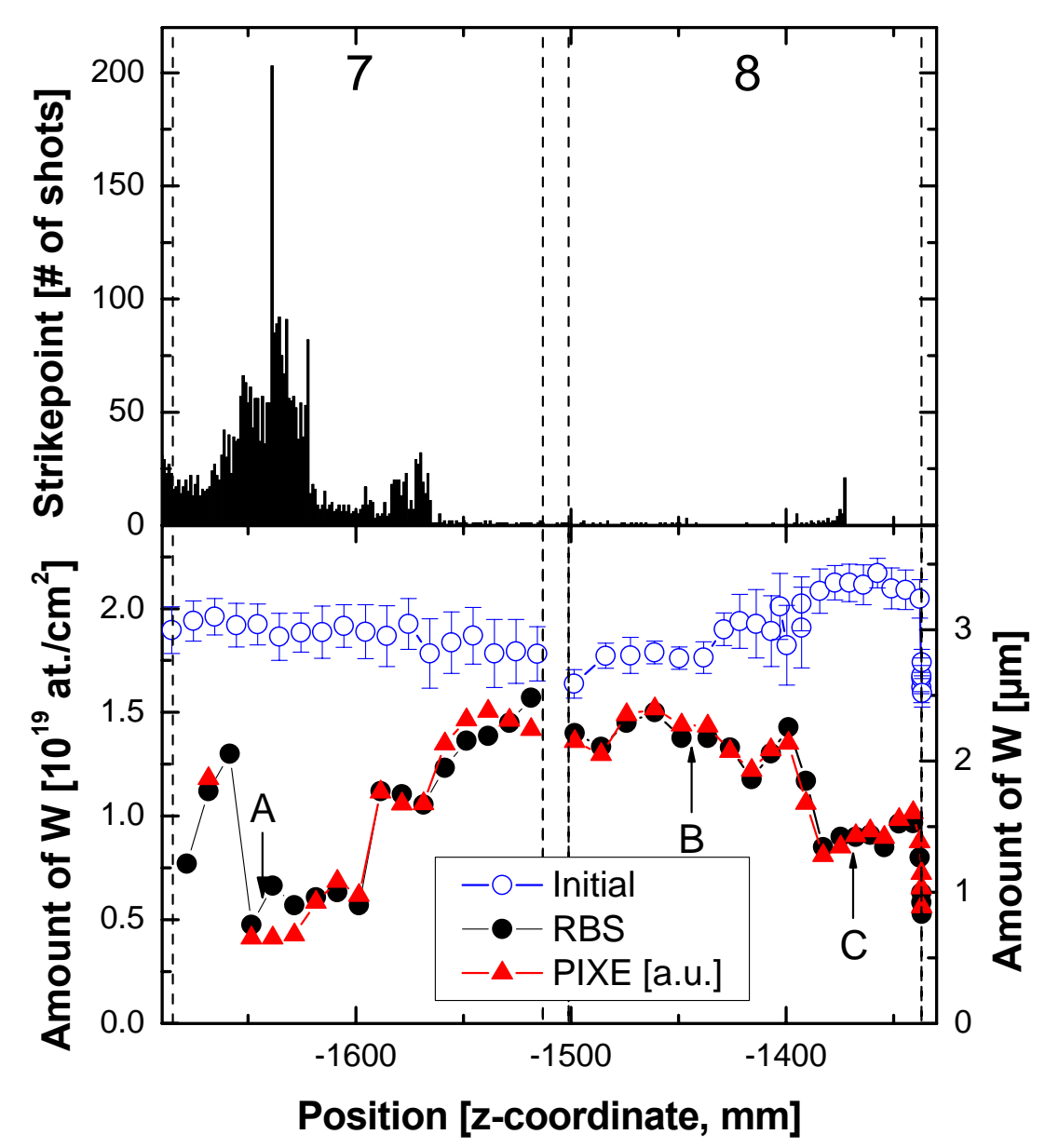

Fig. 2. Top: Number of shots at a specific strike point position in 2001-2004, using a lateral resolution of $1.1 \mathrm{~mm}$ in z-direction. Bottom: Initial W layer thicknesses (hollow points), and remaining thicknesses after exposure. RBS results are quantitative, PIXE results are in arbitrary units. Dashed lines indicate the borders of tiles 7 and 8. Scanning electron micrographs from positions A, B, and C are shown in Fig. 3.

The initial $\mathrm{W}$ layer thicknesses are shown in the lower part of Fig. 2. The error bars of the data points are due to the plural scattering background in the RBS-spectra at $2.5 \mathrm{MeV}$, which cannot be calculated precisely with simulation codes. This background was much smaller for the post-exposure analysis due to the higher proton energy used. The initial layer thickness showed some lateral variation especially on tile 8 due to the complicated tile shape. All data points on the horizontal part of tile 8 (apron, see Fig. 1) have identical z-coordinate.

The remaining $\mathrm{W}$ layer thicknesses after exposure are also shown in the lower part of Fig. 2. The RBS results are quantitative, while the PIXE results are in arbitrary units and scaled to fit the RBS results. RBS and PIXE show good agreement in the spatial distribution of remaining W. PIXE gives only 


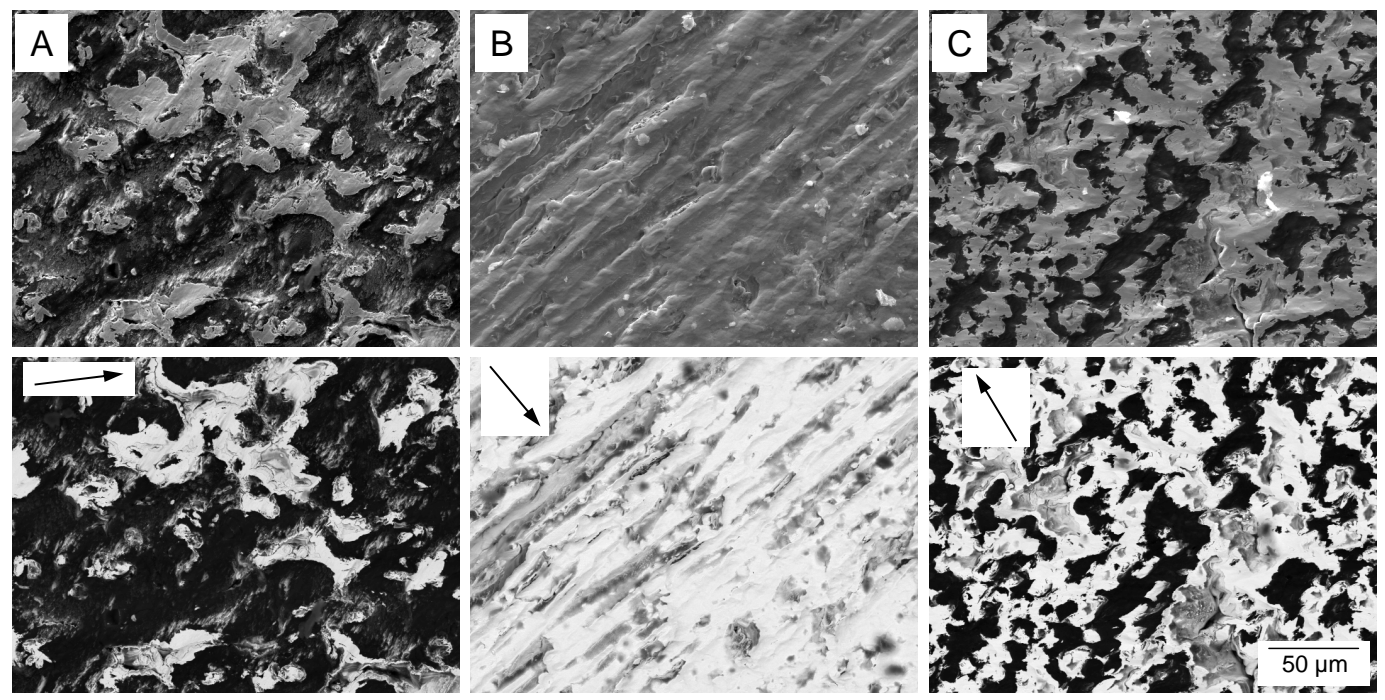

Fig. 3. Scanning electron micrographs of different tile areas after exposure. Positions $\mathrm{A}, \mathrm{B}$, and $\mathrm{C}$ are indicated in Fig. 2. The top row was recorded with secondary electrons, the bottom row shows the same area as the above picture, but recorded with backscattered electrons. Arrows indicate the direction of the incident particle flux.

the total amount of $\mathrm{W}$, and the results are (almost) insensitive to surface roughness and the lateral or depth distribution of $\mathrm{W}$. The detailed shapes of the RBS spectra provide information about surface roughness: the remaining W layer is very rough, with the half width of the thickness variation usually exceeding the mean thickness. The surface is only partly covered with W at many areas.

The largest erosion is observed on tile 7 at the most often used strike point positions from $z=-1650$ to $-1600 \mathrm{~mm}$. About $2.4 \mu \mathrm{m} \mathrm{W}$ (about $75 \%$ of the initial amount) has been eroded in this area. Large erosion is also observed on the upper part of tile 8 with $z>-1400 \mathrm{~mm}$, and on the horizontal part (apron) of tile 8, where also more than $2 \mu \mathrm{m} \mathrm{W}$ (about 60\%) has been removed. The observed erosion is only a lower boundary due to total removal of the $\mathrm{W}$ at some places, see below. Only a small erosion is observed at the top part of tile 7 and the bottom part of tile 8 , where only about $0.4 \mu \mathrm{m} \mathrm{W}$ were removed.

Scanning electron micrographs of different tile areas are shown in Fig. 3. The top row was recorded with secondary electrons (SE). SE images show primarily the surface topography, because SE electrons originate only from a shallow surface layer. The bottom row was recorded with backscattered electrons (BSE) and gives a more pronounced material contrast: the backscattering yield from high-Z elements is higher, so that they appear bright, while low-Z elements appear dark.

Area $\mathrm{B}$ is a low erosion area, and the $\mathrm{W}$ layer is still present. As was proved by energy-dispersive X-ray detection spectroscopy (EDX), grey areas in BSE 
images indicate deposition of low-Z elements (mainly carbon) on top of W. Such a deposition is observed in depressions of the rough CFC substrate in area B. A small carbon deposition on top of $\mathrm{W}$ was also visible in the RBS spectra from this area.

On the high erosion areas $\mathrm{A}$ and $\mathrm{C}$, the $\mathrm{W}$ layer has been fully eroded in some places, and the carbon substrate has been uncovered. On the strike point area A only remnants of the initial layer are still visible. The $\mathrm{W}$ layer was still present in pores and at the bottom of deeper recessions. The remaining $\mathrm{W}$ layer thickness could be estimated at some positions of area A by tilting the sample by $60^{\circ}$, and was of the order of $500 \mathrm{~nm}$, compared to initial $3000 \mathrm{~nm}$. This was confirmed on cross-sections of the remaining $\mathrm{W}$ layer. This shows, that the $\mathrm{W}$ layer was indeed eroded by the plasma, and that the total loss of the layer is not due to delamination. On plasma-exposed parts of the $\mathrm{W}$ layer the near-surface amount of carbon was low, indicating that the remaining tungsten layer was still mostly tungsten metal, which has not transformed to tungsten carbide.

Nevertheless, despite the large erosion even some carbon deposition is visible in recessed parts and inside pores of area $\mathrm{C}$ - this carbon deposition can be identified by the grey color in the BSE image. What is its origin? It was concluded from increased surface temperatures, that the outer divertor turned into a net deposition area during the reversed field campaign in June/July 2003 [19], but it seems unlikely that these layers were still present in 2004 after one additional year of normal field operation. During the last day of operation before the 2004 shutdown ${ }^{13} \mathrm{CH}_{4}$ was puffed into the outer divertor [20]. The puffing was so strong, that the outer divertor turned into a net deposition area, and ${ }^{13} \mathrm{C}$ together with ${ }^{12} \mathrm{C}$ is observed in the RBS spectra. However, the ${ }^{13} \mathrm{C}$ RBS peak is more narrow than the ${ }^{12} \mathrm{C}$ peak, indicating that ${ }^{12} \mathrm{C}$ forms a thicker layer than ${ }^{13} \mathrm{C}$, already present before the additional ${ }^{13} \mathrm{C}$ deposition. The carbon deposition in recessed areas therefore may occur during regular shots. This is supported by the observation of tungsten redeposition together with $\mathrm{C}$ and $\mathrm{Ni}$ at the bottom of pores, which is visible in sample cross-sections observed by SEM.

The inhomogeneous erosion is mainly due to the roughness of the CFC substrate. This is shown in Fig. 4. Areas inclined towards the incident particle flux are strongly eroded, while areas at the back side of ridges show a smaller erosion or even deposition of low-Z elements on top of the $\mathrm{W}$, as can be seen from the grey areas in the BSE image. A similar observation is made inside pores, where low-Z elements are deposited on top of the $\mathrm{W}$.

It can be seen from Fig. 4, that areas where the W layer has disappeared are recessed compared to areas still covered with $\mathrm{W}$. This indicates net carbon erosion, which exceeds the erosion of $\mathrm{W}$ : once the $\mathrm{W}$ has disappeared, the 

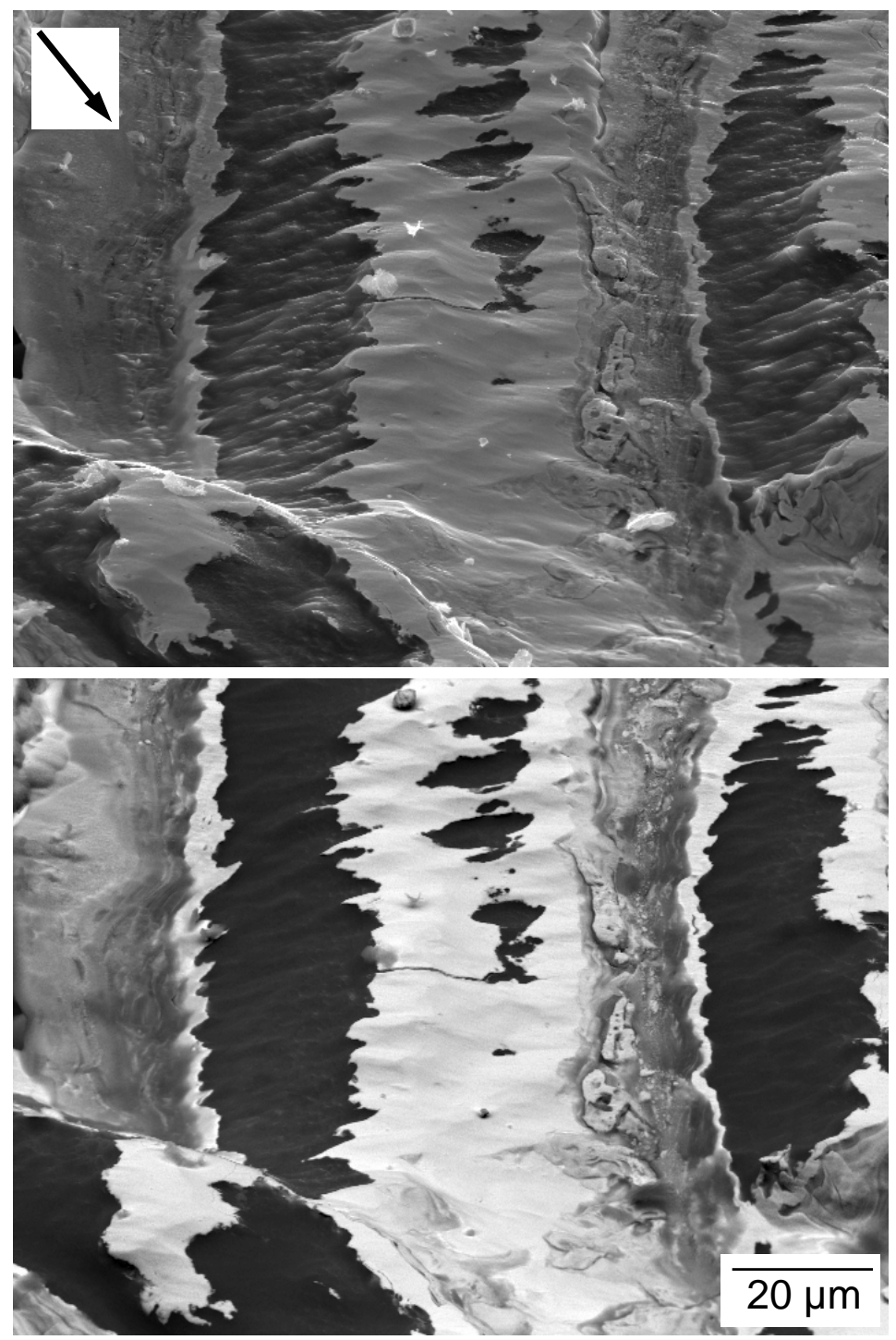

Fig. 4. Scanning electron micrographs of the surface at position B (see Fig. 2). Top: secondary electrons; bottom: backscattered electrons. The sample was tilted by $50^{\circ}$. The arrow indicates the direction of the incident particle flux.

carbon is eroded faster, resulting in pitting. A quantification of the carbon erosion, however, is difficult.

As was already shown in [21], at typical divertor plasma temperatures of 5$40 \mathrm{eV}$ the erosion of $\mathrm{W}$ by $\mathrm{D}$ is negligible, and $\mathrm{W}$ erosion is due to sputtering by beryllium and carbon impurities from the main chamber. The $\mathrm{W}$ erosion on the strike point tile 7 can be explained quantitatively by impurity sputtering: The largest erosion is observed at the strike point location, where also the largest incident fluxes are expected. A carbon concentration of about $0.5-1 \%$ in the incident flux is sufficient to explain the erosion at the strike point, taking prompt redeposition into account [22]. The erosion on tile 8 could be due to ELM filaments [23], strike point jumps [24], fast particles created by 
ICRH and/or LH antennas, or disruptions.

The observed mean tungsten erosion is an upper boundary for a full tungsten divertor, because tungsten eroded from the marker stripe cannot be replaced by tungsten arriving from neighboring tiles, as would be the case for a full tungsten divertor. However, due to the inhomogeneous erosion, the maximum erosion will largely exceed the mean erosion, and may approach the values observed in our measurements. This has to be kept in mind when deciding tungsten coating thicknesses for the ITER like wall project at JET [12].

\section{Conclusions}

The erosion of a tungsten marker stripe from the outer JET divertor exposed during the discharge period 2001-2004 was investigated. Strong tungsten erosion of more than $2.4 \mu \mathrm{m}$ is observed at the strike point area. Strong tungsten erosion is also observed at the upper part and apron of tile 8. The $\mathrm{W}$ marker layer has been fully eroded in some places. While the erosion on the strike point tile 7 can be explained by sputtering by carbon and beryllium impurities, the erosion on tile 8 is less clear.

The erosion is strongly inhomogeneous due to surface roughness on the scale of several $10 \mu \mathrm{m}$, with a high erosion at areas inclined towards the incident particle flux, and a smaller erosion (and often even deposition) at the far side of microscopic ridges and at the bottom of recessions and pores. This inhomogeneous erosion with a much larger maximum erosion than the mean has to be kept in mind when deciding tungsten coating thicknesses.

Areas with total removal of the $\mathrm{W}$ layer are more strongly eroded and recessed (pitting), showing that the outer divertor is a net carbon erosion area. The erosion of carbon exceeds the erosion of $\mathrm{W}$, but is difficult to quantify. As was shown by ${ }^{13} \mathrm{CH}_{4}$ puff experiments from the outer divertor, some fraction of the ${ }^{13} \mathrm{C}$ is transported to the inner divertor [20]. Combined with the observation of net carbon erosion in the outer divertor, this may indicate that some fraction of the carbon deposition in the inner divertor originates from the outer divertor, in addition to carbon and beryllium originating from sputtering at the main chamber walls.

\section{Acknowledgements}

Ion beam analysis measurements by T. Dittmar and the technical assistance of J. Dorner and M. Fußeder are gratefully acknowledged. Calculated cross- 
section data for ${ }^{12} \mathrm{C}(\mathrm{p}, \mathrm{p}){ }^{12} \mathrm{C}$ scattering above $3.5 \mathrm{MeV}$ were provided by A. Gurbich.

\section{References}

[1] J.P. Coad, P. Andrew, D.E. Hole, S. Lehto, J. Likonen, G.F. Matthews, M. Rubel, and Contributors to the EFDA-JET work-programme. J. Nucl. Mater. 313-316 (2003) 419.

[2] M. Rubel, J.P. Coad, N. Bekris, S.K. Erents, D. Hole, G.F. Matthews, R.-D. Penzhorn, and Contributors to EFDA-JET work programme. J. Nucl. Mater. 313-316 (2003) 321.

[3] J. Likonen, J.P. Coad, E. Vainonen-Ahlgren, T. Renvall, D.E. Hole, M. Rubel, and JET-EFDA Contributors. J. Nucl. Mater. (2007) . these proceedings.

[4] M. Mayer, V. Rohde, J. Likonen, E. Vainonen-Ahlgren, K. Krieger, X. Gong, J. Chen, and ASDEX Upgrade Team. J. Nucl. Mater. 337-339 (2005) 119.

[5] D.G. Whyte, J.P. Coad, P. Franzen, and H. Maier. Nucl. Fusion 39 (1999) 1025.

[6] M. Mayer, R. Behrisch, P. Andrew, and A.T. Peacock. J. Nucl. Mater. 241-243 (1997) 469.

[7] G.F. Matthews, M. Stamp, P. Coad, J. Likonen, V. Philipps, M. Rubel, J.D. Strachan, and JET EFDA Contributors. Material migration in JET. In 30th EPS Conference on Controlled Fusion and Plasma Physics (2003), vol. 27A of europhysics conference abstracts, pp. P-3.198.

[8] G.F. Matthews. J. Nucl. Mater. 337-339 (2005) 1.

[9] M.J. Rubel, J.P. Coad, K. Stenström, P. Wienhold, J. Likonen, G.F. Matthews, and V. Philipps. J. Nucl. Mater. 329-333 (2004) 795.

[10] S.L. Allen, W.R. Wampler, A.G. McLean, D.G. Whyte, W.P. West, P.C. Stangeby, N.H. Brooks, D.L. Rudakov, V. Phillips, M. Rubel, G.F. Matthews, A. Nagy, R. Ellis, and A.S. Bozek. J. Nucl. Mater. 337-339 (2005) 30.

[11] D.G. Whyte, R. Bastasz, J.N. Brooks, W.R. Wampler, W.P. West, C.P.C. Wong, O.I. Buzhinskij, and I. V. Opimach. J. Nucl. Mater. 266-269 (1999) 67.

[12] J. Paméla, G.F. Matthews, V. Philipps, R. Kamendje, and JET-EFDA Contributors. J. Nucl. Mater. (2007) . these conference proceedings.

[13] S. Lehto, J. Likonen, J.P. Coad, T. Ahlgren, D.E. Hole, M. Mayer, H. Maier, P. Andrew, and J. Kolehmainen. Fusion Eng. Des. 66-68 (2003) 241.

[14] M. Mayer. SIMNRA user's guide. Tech. Rep. IPP 9/113, Max-Planck-Institut für Plasmaphysik, Garching, 1997. 
[15] M. Mayer. SIMNRA, a simulation program for the analysis of NRA, RBS and ERDA. In Proceedings of the 15th International Conference on the Application of Accelerators in Research and Industry (1999), J. L. Duggan and I. Morgan, Eds., vol. 475 of AIP Conference Proceedings, American Institute of Physics, p. 541.

[16] A.F. Gurbich. Nucl. Instr. Meth. 136-138 (1998) 60.

[17] E. Kashy, R.R. Perry, R.L. Steele, and J.R. Risser. Phys. Rev. 122, 3 (1961) 884 .

[18] A.F. Gurbich. Nucl. Instr. Meth. 129 (1997) 311.

[19] P. Andrew, J.P. Coad, Y. Corre, T. Eich, A. Herrmann, G.F. Matthews, J.I. Paley, L. Pickworth, R.A. Pitts, M.F. Stamp, and JET EFDA Contributors. J. Nucl. Mater. 337-339 (2005) 99.

[20] J.P. Coad, P. Andrew, D. Hole, J. Likonen, M. Mayer, M. Rubel, J.D. Strachan, E. Vainonen-Ahlgren, A. Widdowson, and JET-EFDA Contributors. J. Nucl. Mater. (2007) . these proceedings, presented at PSI 2006.

[21] A. Thoma, K. Asmussen, R. Dux, K. Krieger, A. Herrmann, B. Napiontek, R. Neu, J. Steinbrink, M. Weinlich, U. Wenzel, and the ASDEX Upgrade Team. Plasma Phys. Controlled Fusion 39 (1997) 1487.

[22] A. Kirschner. Personal communication. 2006.

[23] R.A. Pitts, W. Fundamenski, S.K. Erents, Y. Andrew, A. Loarte, C. Silva, and JET-EFDA contributors. Nucl. Fusion 46 (2006) 82.

[24] E.R. Solano, S. Jachmich, F. Villone, N. Hawkes, Y. Corre, A. Loarte, R.A. Pitts, K. Guenther, A. Korotkov, M. Stamp, P. Andrew, J. Conboy, A. Cenedese, M. Kempenaars, T. Bolzonella, E. Rachlew, G.F. Mattews, and JET EFDA contributors. ELMs, strike point jumps and SOL currents. In Proceedings of the 20th Fusion Energy Conference (2005), IAEA, pp. EX/P13. 